\title{
Forensic veterinary evaluation of gunshot wounds to a dog's head based on traditional examination methods and modern imaging techniques
}

\author{
KINGA PANASIUK-FLAK, MAŁGORZATA GRELA, PIOTR LISTOS, \\ MAGDALENA GRYZIŃSKA*, GRZEGORZ BUSZEWICZ**, \\ WOJCIECH CHAGOWSKI**, GRZEGORZ TERESIŃSKI**
}

\begin{abstract}
Department and Clinic of Animal Internal Diseases, Sub-Department of Pathomorphology and Forensic Medicine, Faculty of Veterinary Medicine, University of Life Sciences in Lublin, Głęboka 30, 20-612 Lublin, Poland *Institute of Biological Basis of Animal Production, Faculty of Biology, Animal Sciences and Bioeconomy, University of Life Sciences in Lublin, Akademicka 13, 20-950 Lublin, Poland

**Department of Forensic Medicine, II Faculty of Medicine with English Language Division, Medical University of Lublin, Jaczewskiego 8, 20-090 Lublin, Poland
\end{abstract}

\section{Panasiuk-Flak K., Grela M., Listos P., Gryzińska M., Buszewicz G., Chagowski W., Teresiński G. Forensic veterinary evaluation of gunshot wounds to a dog's head based on traditional examination methods and modern imaging techniques}

\section{Summary}

At present, the most common method of analysis of gunshot wounds is necropsy, but modern imaging methods, such as X-ray (RTG) and computed tomography (CT), are gaining in popularity. We conducted an experiment involving shooting at test material from various distances $(0 \mathrm{~m}, 1.5 \mathrm{~m}, 15 \mathrm{~m})$ with bullets of various calibres in order to obtain characteristic gunshot wounds and compare the utility of the traditional autopsy method and modern imaging methods for forensic veterinary purposes. Then, a digital $X$-ray and computed tomography scan as well as a necropsy, were performed. The analysis of the results of the experiment with ammunition of different calibres showed that damage caused by a shot from a firearm is correlated with the calibre, initial velocity and kinetic energy of the projectile, as well as the distance from the barrel end to the object being shot. In the 12 cases analysed, $80 \%$ of the bullets fired from different distances had sufficient kinetic energy to exit the test material after passing through the tissue. A macroscopic necropsy supplemented by modern imaging methods is the most accurate means of forensic veterinary analysis of gunshot wounds in animals.

Keywords: forensic veterinary, gunshot injuries, digital radiography, computed tomography scan, postmortem examination

With the continually increasing availability of firearms and popularity of gun-related recreation, such as hunting and sports shooting, as well as the increasing number of illegal firearms associated with criminal activity, the number of shooting incidents is increasing as well. The legal status of the possession of weapons is strictly regulated by the provisions of the Act on arms and ammunition (8), which precisely classifies types of firearms and ammunition, as well as carefully defines the rights of citizens to own weapons. With an upward trend in the number of firearms, the risk of accidental and deliberate injuries caused by their use is increasing. However, these injuries have been shown to result more frequently from suicide attempts than from acts of violence or unskilled handling of firearms $(2,3,6,10)$.
Very often the victims of shooting are animals. Analysis of their injuries is extremely useful in determining the time of death or the circumstances of a crime. The domestic dog, because of its ability to adapt to almost any conditions and the role it plays in the environment and in serving human beings, has become the animal most vulnerable to gunshot wounds $(13,16,17)$.

As a subject of forensic medical opinions, gunshot wounds are a significant challenge because they involve injuries to multiple organs, which necessitates numerous multi-faceted examinations. In these wounds, there is a considerable disproportion between the small area of the mechanical trauma and the substantial degradation of tissues due to the kinetic energy 
of the projectile. Hence a gunshot wound cannot be assessed by examining the entrance and exit wounds alone $(4,17)$. In order to establish the trajectory of the bullet and analyse tissue damage, a combination of traditional examination methods and modern imaging techniques seems to be necessary $(18,21)$.

Gunshot wounds ought to be analysed by the most effective methods so as to establish the track of the projectile, traces on the surface of the skin, mechanical damage caused in the body, and the location of the bullet embedded in the tissues of the victim. Given the increasing frequency of the problem, there is a need to compare research methods, which should optimally be highly sensitive, specific, simple and relatively cheap (22).

In the empirical part of this paper, we present methods for a precise analysis of gunshot wounds. The specificity and utility of each method were compared, including traditional post-mortem examination and modern imaging techniques, i.e. radiological methods, including x-ray and computed tomography.

\section{Material and methods}

For purposes of the experiment, tests were conducted involving shooting at experimental surfaces, in this case heads of domestic dogs (Canis lupus familiaris), from various distances in order to obtain a complete picture of gunshot wounds depending on the type of weapon and ammunition used and the distance from the muzzle of the gun to the research material.

Both the shooting distance and the type of weapon and ammunition used were consistent with the most common cases of gunshot wounds in animals (examined at the request of judicial authorities). The research material consisted of 11 domestic mixed-breed dogs bred by amateur breeders, which due to advanced age and progressive atrophy (marasmus senilis) had a poor prognosis, which was an indication for euthanasia. The dogs' weight varied between $5-27 \mathrm{~kg}$. The dogs were euthanized by intravenous injection with Morbital 0,3-0,6 ml/kg b.w. (sodium pentobarbital 39,99$-79,98 \mathrm{mg} / \mathrm{kg}$ b.w. and pentobarbital 8,01-16,02 mg/kg b.w.) and after death were donated by their owners for scientific and research purposes.

The experiment was divided into four steps, carried out in immediate succession. First, the test material was prepared by separating the head from the torso at the height of the cervical vertebrae. The material was placed in numbered plastic bags and, after completion of necessary formalities, transported to the shooting range. At stands specially prepared for this purpose, firearms were fired in the direction of the appropriately positioned heads. Twelve shots were fired: one contact shot with the muzzle applied directly to the head in the area of the frontal bone, 7 shots from a distance of $1.5 \mathrm{~m}$, and 4 from a distance of $15 \mathrm{~m}$. Subsequently, digital X-ray (RTG) and computed tomography (CT) scan were performed. Radiographic examinations were carried out using a fully automated Agfa DX-D 600 radiography system with a fixed digital caesium iodide detector $(43 \times 43 \mathrm{~cm})$ and an NX acquisition station with the Musica3 image processing algorithm. Tomographic imaging was per- formed using a Toshiba Astelion Advance Edition 16-row CT system. The acquisition parameters were as follows: spiral sequence, $0.5 \mathrm{~mm}$ layer thickness, $120 \mathrm{kV}$ voltage, automatic current modulation in the range of 50-320 mA, AIDR iterative reconstruction algorithm and $0.75 \mathrm{~s}$ rotation time. The elements being scanned were placed as close as possible to the longitudinal axis of the gantry, and the narrowest possible field of view (FOV) was used to achieve the best possible resolution and the smallest possible voxel size. Diagnostic images were reconstructed on the acquisition console using standard filters for evaluating soft tissues and bone structures, as well as additional protocols for highresolution reconstruction of the skull base and dentition structures with compensation algorithms for the presence of foreign bodies. Then the material was transported for a necropsy and macroscopic photographic documentation.

\section{Results and discussion}

The research clearly demonstrates the danger associated with the use of firearms. The extent of gunshot wounds depends on the type and energy of the projectile, as well as the distance from the end of the barrel to the object being shot.

In the 12 cases analysed, $80 \%$ of the bullets fired from different distances had sufficient kinetic energy to exit the test material after passing through the tissue. Superficial injuries without penetration of the cranium were observed in only one head, which was shot with a shotgun shell from a distance $15 \mathrm{~m}$.

The results of the experiment on the animal model clearly indicate that a contact shot or a shot fired from a distance of $1.5 \mathrm{~m}$ or $15 \mathrm{~m}$ may result in extensive injuries to tissues and the skeleton. The nature, type and extent of injuries that were found in the cranial cavity would result in certain death of the victim. The analysis of the results of the experiment performed using ammunition of different calibres also showed that the damage caused by a shot from a firearm is correlated with the calibre, initial velocity and kinetic energy of the projectile, as well as the distance from the barrel end to the object being shot.

A shot with a bullet, irrespective of the calibre, in each case was found to cause numerous, comminuted fractures in the skull, as well as destruction of brain tissue. A contact shot with a.38 Wadcutter calibre bullet caused mechanical damage to the brain tissue in numerous locations, but due to the rapid loss of energy when the bullet encounters the barriers of bone and soft tissue, it may fail to exit the test material, resulting in the absence of an exit wound (Fig. 1,2). A shot with a.22 calibre Long Rifle ACP bullet from $1.5 \mathrm{~m}$ completely destroyed the brain tissue because of the tendency of the bullet to ricochet in the tissue of the test material. It also caused the appearance of bullet fragments, each of which moved through the material with a specific kinetic energy until this energy was exhausted. This can also cause fragments of the bullet to remain in tissues, as they lack sufficient energy to pierce the bone barrier (Fig. 3, 4). 

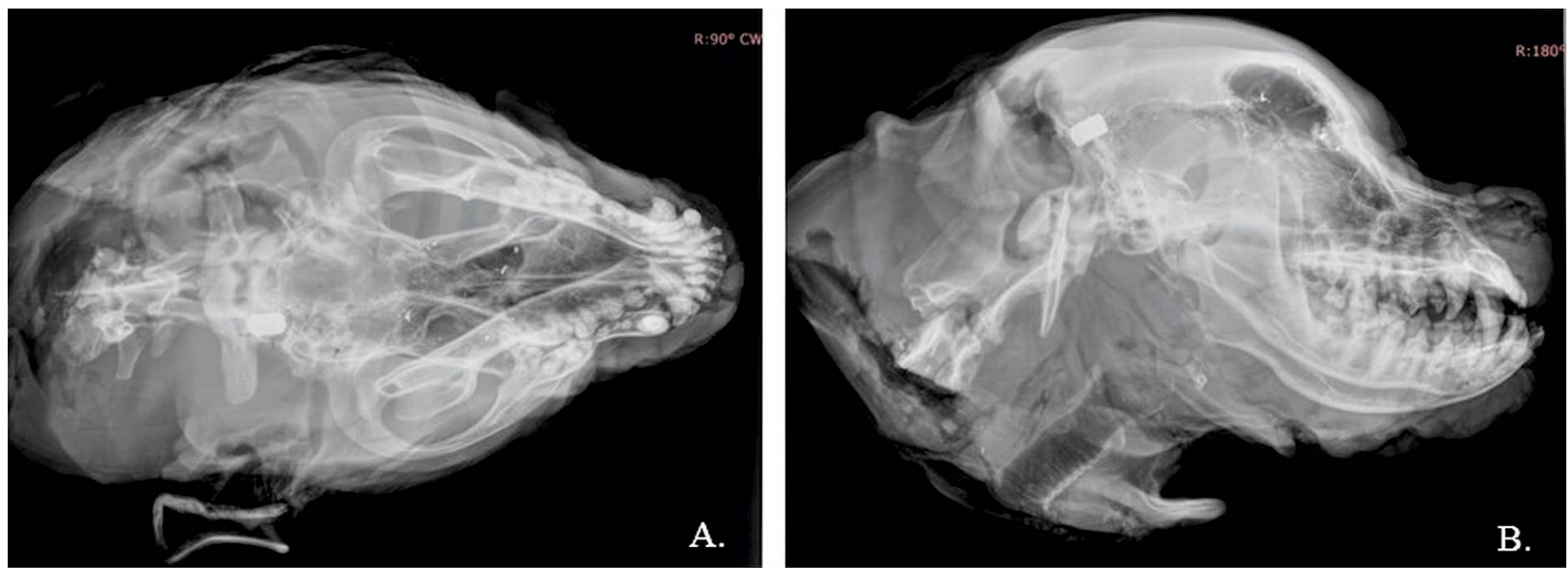

Fig. 1. Radiograph of the test material after a contact shot with a .38 Wadcutter calibre bullet; (A) dorso-ventral view, (B) latero-lateral view

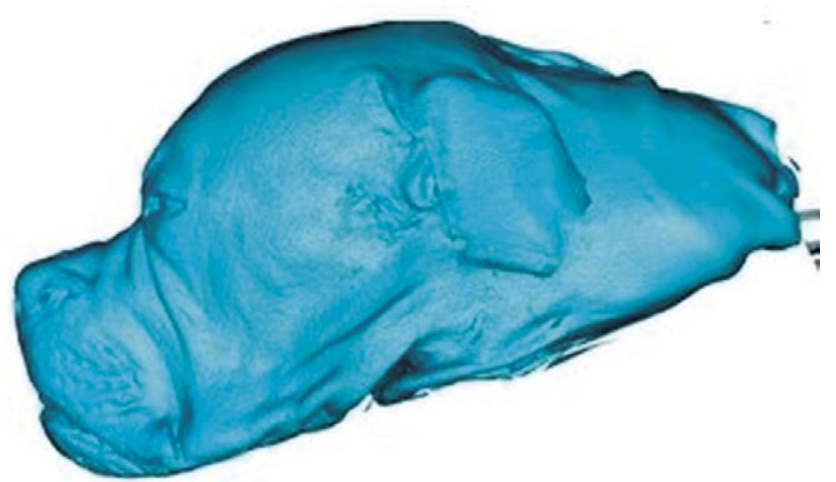

A shot with shotgun pellet from a distance of $1.5 \mathrm{~m}$ created an entrance wound with the largest diameter and caused the most damage to the skeleton, brain tissue and other soft tissues. This was due to the large diameter of the projectile. When piercing the skin, it behaves like a fixed cartridge and does not split into individual pellets until it reaches the brain tissue, as evidenced by the high concentration of pellet agglomerates in the occipital area and in the cervical segment (Fig. 5).

A shot in the head with a shotgun pellet from a distance of $15 \mathrm{~m}$ caused the presence of numerous shot pellets in the subcutaneous and muscle tissue in the vicinity of the gunshot. There was no damage to the skeleton or brain tissue (Fig. 6, 7). It can therefore be concluded that the shooting of an animal (dog) in the circumstances of the experiment need not directly result in death, but the likelihood of numerous injuries to a living animal is very high. Analysis of the area around the injuries shows that they would have been very likely to cause pain and suffering to the animal, as referred to in the provisions of the Animal Protection Act (9).

The modern imaging methods (RTG and CT) used in the experiment are of great importance in the forensic assessment of gunshot wounds in cases where a macroscopic examination is problematic, e.g. in the case of suspected infectious disease or where it is precluded by advanced decomposition. As a supplement to the basic post-mortem examination, they are essential for a more thorough evaluation of the material. Both RTG and $\mathrm{CT}$ are more accurate than the classical post-mortem examination in revealing foreign objects embedded in tissues, such as bullets or bullet fragments. An obvious limitation of RTG as compared to CT is its incapability of locating them precisely $(5,19)$.

Gunshot wounds are unquestionably a domain of tactical and combat medicine. Nevertheless, as a result of increasing access to firearms, gunshot wounds in people and animals are a significant problem in medigraphy image of the test material after a contact shot with a .38 Wadcutter calibre bullet 

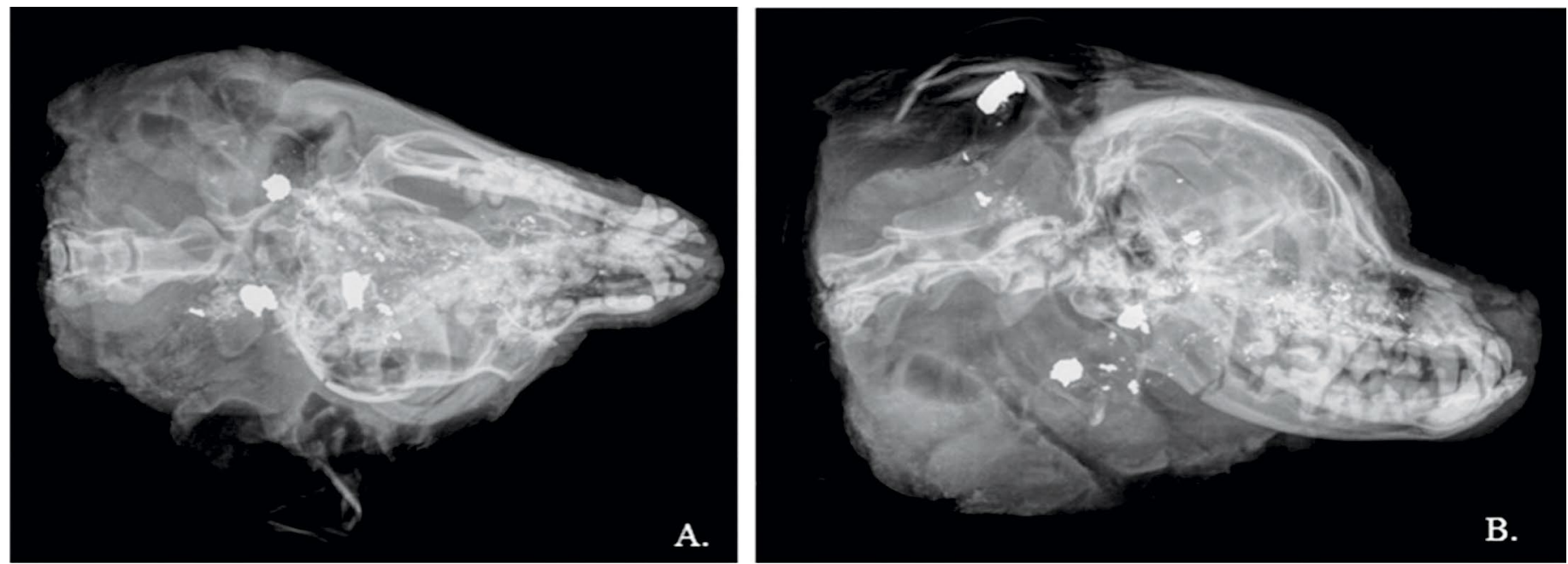

Fig. 3. Radiograph of the test material after a shot with a .22 calibre bullet fired from a distance of $1.5 \mathrm{~m}$. (A) dorso-ventral view, (B) latero-lateral view
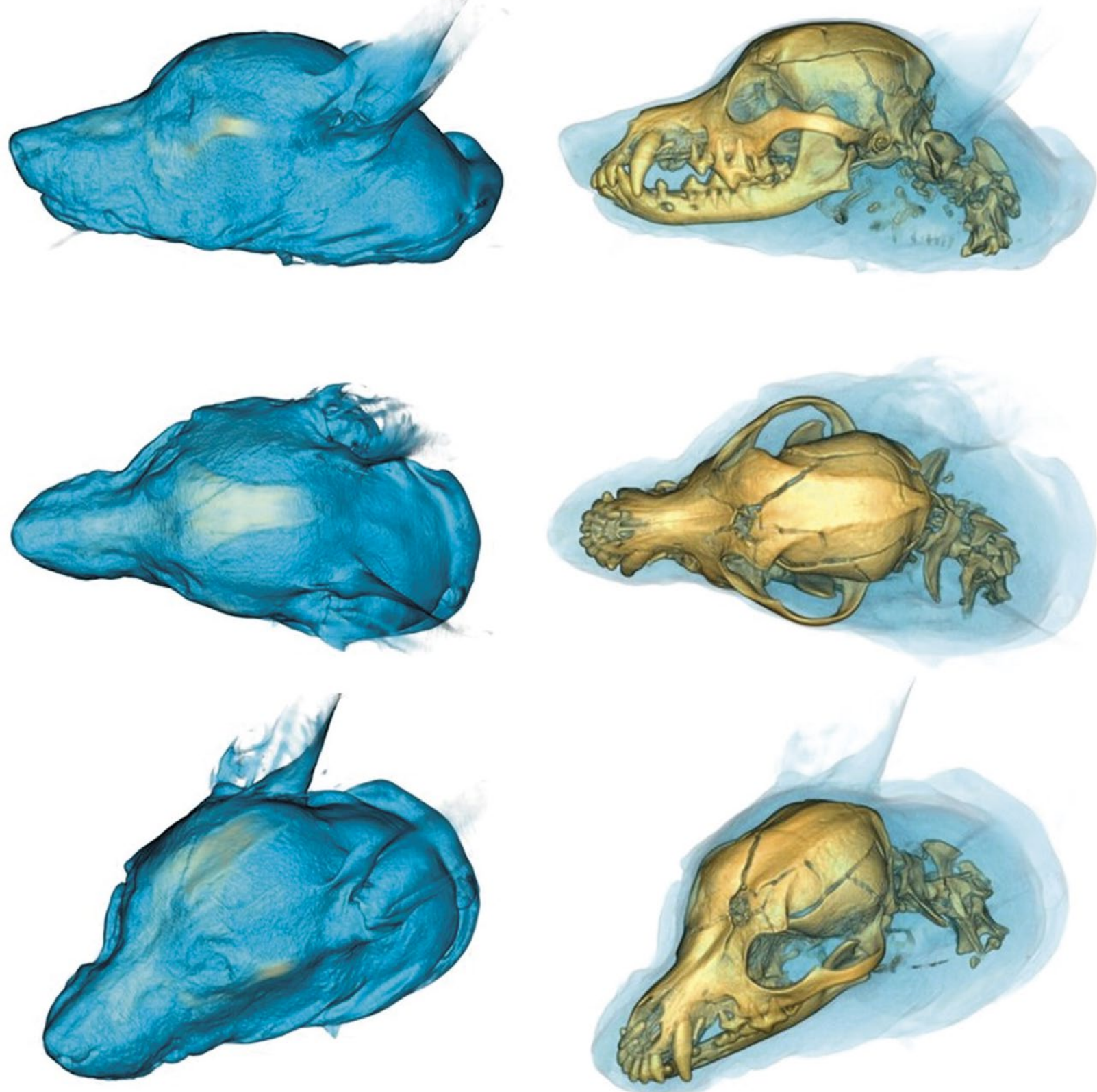

Fig. 4. Three-dimensional volume-rendered computer tomography image of the test material after a shot with a .22 calibre bullet fired from a distance of $1.5 \mathrm{~m}$ 

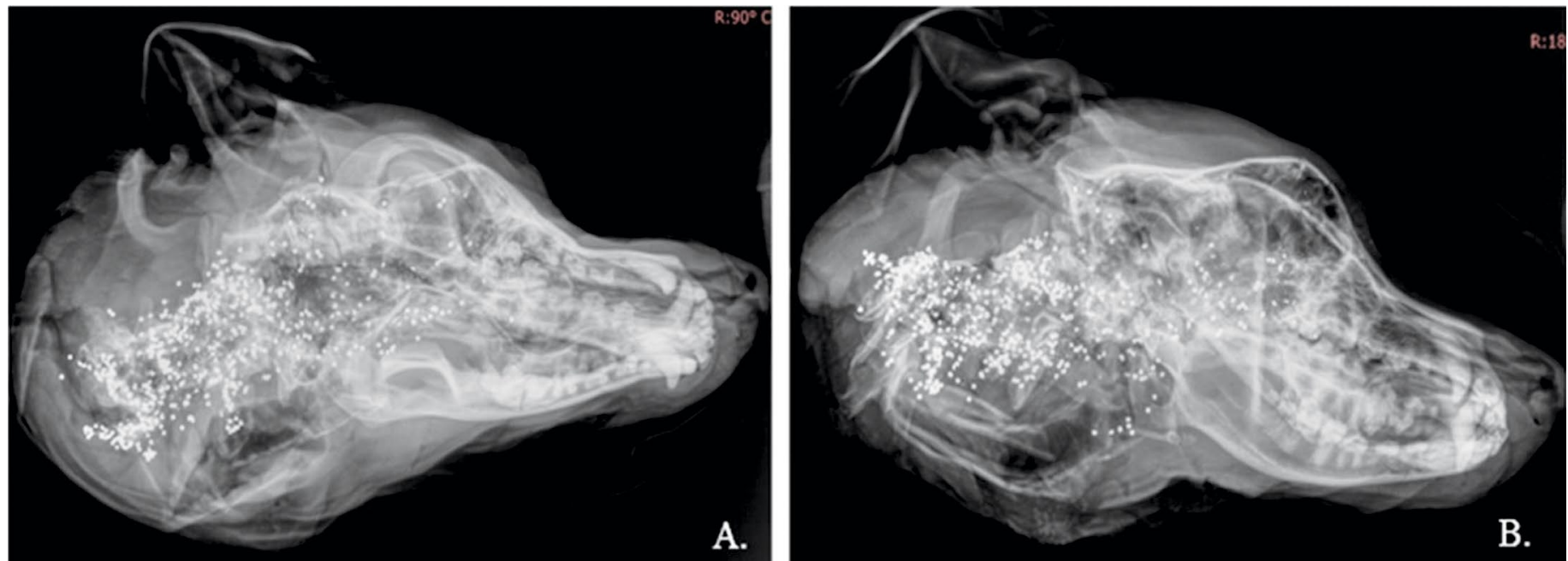

Fig. 5. Radiograph of the test material after a shot with a 12-gauge shotgun pellet fired from a distance of $1.5 \mathrm{~m}$. (a) dorso-ventral view, (b) latero-lateral view
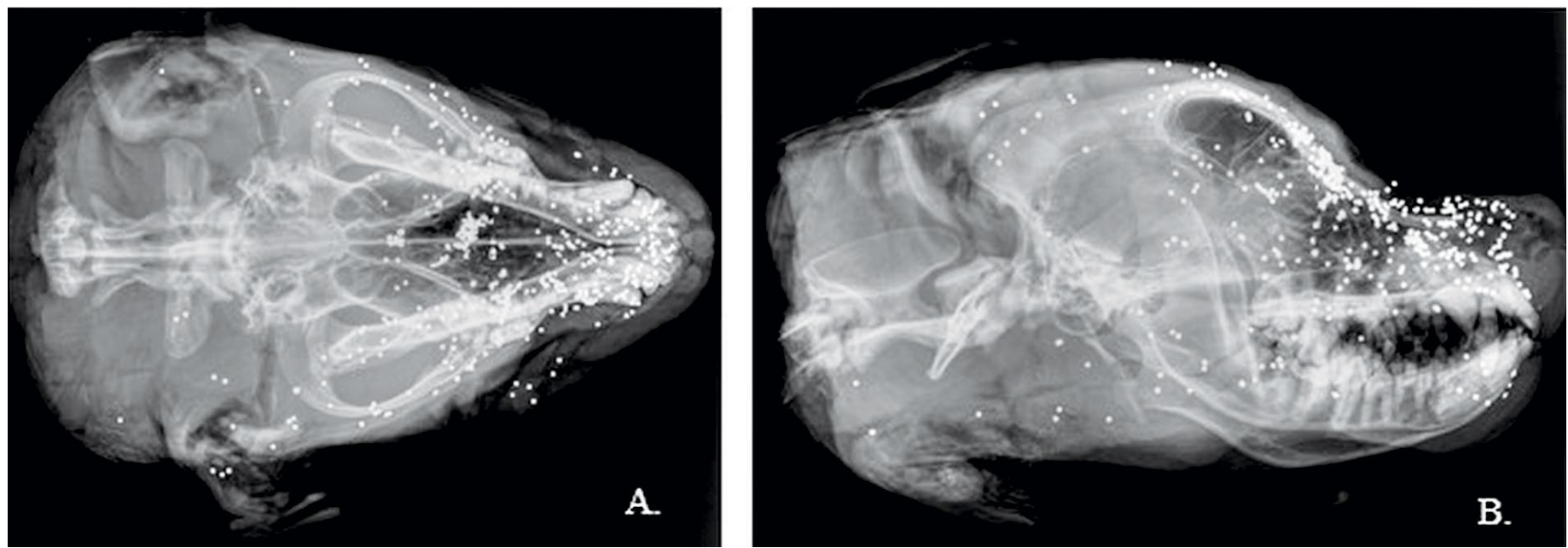

Fig. 6. Radiograph of the test material after a shot with a 12-gauge shotgun pellet fired from a distance of $15 \mathrm{~m}$. (a) dorso-ventral view, (b) latero-lateral view
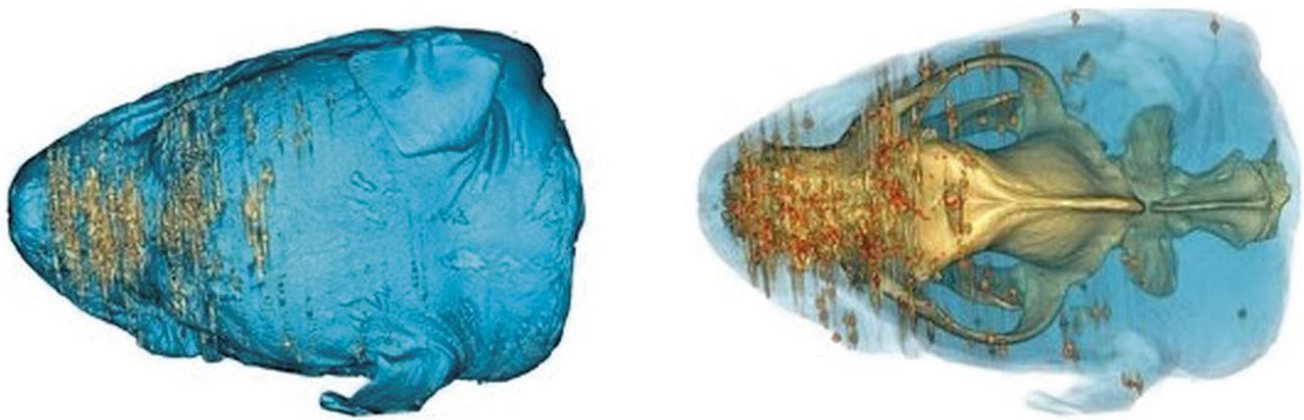

Fig. 7. Three-dimensional volumerendered computer tomography image of the test material after a shot with a 12-gauge shotgun pellet fired from a distance of $15 \mathrm{~m}$
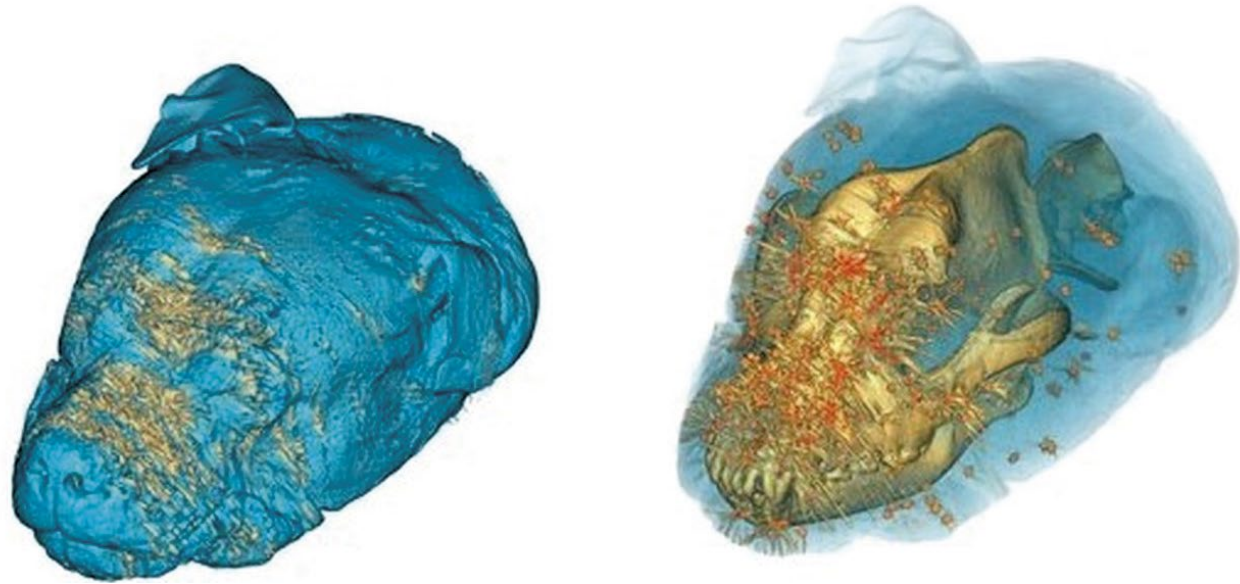
cal and veterinary practice even in periods of relative peace. Gunshot wounds, because of the damage to the body, are included among traumas that require detailed diagnosis, specialized surgical procedures and rehabilitation. Another specific characteristic of gunshot wounds is that they usually affect multiple organs and often result in the death of the victim. The mechanism by which such injuries occur is extremely complex and depends on the type of weapon used, the type and speed of the projectile, and the distance from which it was fired $(7,14,20)$.

In cases involving gunshots, in order to determine the motive, identify the perpetrator and, most importantly, make a proper legal assessment of the incident, each stage of analysis is important. The first step is to secure the traces at the scene of the incident, which is done by forensic technicians. Then, an in-depth analysis of these traces is made, based on which conclusions can be drawn about the course of the incident. Another crucial step is an examination by specialist doctors and expert witnesses appointed for this purpose $(1,11,12)$. Multifaceted analyses provide information on a number of crucial questions regarding the characteristics of gunshot injuries. By performing specialized tests, an expert veterinarian is able to establish the location and characteristics of the entrance and exit wounds, determine the extent of the injuries, and thereby determine the exact track of the bullet in the victim's body. This information is essential in solving criminal cases involving the use of firearms $(15,22)$.

It has been established that a traditional post-mortem examination can be a very important preliminary element in preparing an opinion regarding gunshot injuries. This should be a basic examination because it is an empirical assessment of pathological changes in the material. Morphological and biophysical changes found in the material make it is possible to classify entrance and exit wounds as well as to analyse damage to the hair coat and the accompanying effect of fouling or deposition of unburned particles of powder (stippling).

In conclusion, a macroscopic necropsy supplemented by modern imaging methods is the most accurate means of forensic veterinary analysis of gunshot wounds in animals. It combines several methods, making it possible to assess the injuries sustained by the victim and to determine circumstances of the incident, such as the shooter's position, the shooting distance, as well as the weapons and ammunition used. Thus it provides the most reliable basis for a forensic veterinary examination and further criminalistics studies, leading to an eventual material truth.

\section{References}

1. Babinska I., Kusiak D., Szarek J., Lis A., Lyko A., Maciejewska M., Szweda M. Giving forensic veterinary opinions on conflict situations regarding poultry. Med. Weter. 2017, 73, 239-243.

2.Bloch-Boguslawska E., Engelgardt P., Paradowska A.: Gunshot wounds in the material of Forensic Medicine Institute, Collegium Medicum, Nicolaus Copernicus University in Bydgoszcz. Arch. Med. Sad. 2007, 57, 313-317.
3. Branas C. C., Richmond T. S., Culhane D. P., TenHave T. R., Wiebe D. J.: Investigating the Link Between Gun Possession and Gun Assault. Am. J. Public Health 2009, 99, 2034-2040.

4. Grabherr S., Grimm J., Heinemann A.: Atlas of Postmortem Angiography Springer, Berlin 2016.

5. Grela M., Listos P., Gryzińska M., Teresiński G., Chagowski W., Buszewicz G. Imaging techniques as a method of sectional examination in forensic veterinary medicine. Med. Weter. 2018, 74, 751-758.

6. Huemer M.: Is There a Right to Own a Gun? Soc. Theory Pract. 2003, 29, 297-324.

7. Jaklinski A., Kobiela J. S.: Forensic medicine. Państwowy Zakład Wydawnictw Lekarskich, Warszawa 1972.

8. Journal of Laws, No. 111, item 724 (Ustawa z dnia 21 sierpnia 1997. O ochronie zwierząt, nr 111 poz. 724 t.j. Dz. U. 2013 poz. 856, 2014 poz. 1794, 2015 poz. 266, 2016 poz. $1605,1948,2102,2017$ poz. 60) Dz. U. 1997, 111, 3445-3453.

9. Journal of Laws, No. 53, item 549 (Ustawa z dnia 21 maja 1999. O broni i amunicji, t.j. Dz. U. 2012 poz. 576, 2013 poz. 829, 2014 poz. 295, 2015 poz. 1505, 2016 poz. 1948, 1954). Dz. U. 1999; 53: 2888-2896.

10. LaFollette H.: Gun Control. Ethics 2000, 110, 263-281.

11. Listos P., Gryzinska M., Batkowska J.: Postmortem decrease in temperature in the orbit of dogs for use in determining time of death. Slov. Vet. Res. 2016, 53, 85-90.

12.Listos P., Gryzińska M., Batkowska J., Dylewska M., Dudzinska E., Piorkowski J.: Preliminary study on the estimation of the time of death in animals based on microflora development in a dog's gastrocnemius muscle. Med. Weter. 2017, 73, 229-233.

13. Listos P., Komsta R., Lopuszynski W., Gryzinska M., Teresinski G. Chagowski W., Buszewicz G., Dylewska M.: Radiological and forensic veterinary analysis of gunshot cases in eastern Poland. Med. Weter. 2016, 72, 453-457.

14. Nozdryn-Plotnicki Z., Listos P., Lopuszynski W., Debiak P.: Section investigation of animals wounded from fire arms: some remarks. Med. Weter. 2005, 61, 887-889

15. Oehmichen M., Gehl H. B., Meissner C., Petersen D., Höche W., Gerling I., König H.G.: Forensic pathological aspects of postmortem imaging of gunshot injury to the head: documentation and biometric data. Acta Neuropathol. 2003, 105, 570-580.

16. Pavletic $M$. .. : Gunshot wounds in veterinary medicine: projectile ballistics. Compend. Contin. Educ. Pract. Vet. 1986, 8, 47-60.

17. Plesiak M., Stankiewicz Z., Jaroszewski J., Szwed R., Gnus J., Pfanhauser M. Gunshot of the right buttock - case report. Chirurgia Polska 2011, 13, 83-89.

18. Ro T., Murray R., Galvan D., Nazim M. H.: A typical gunshot wound: Bullet trajectory analyzed by computed tomography. Int. J. Surg. Case Rep. 2015, 14, 104-107.

19. Roberts I. S. D., Benamore R. E., Benbow E. W., Lee S. H., Harris J. N., Jackson A., Mallett S., Patankar T., Peebles C., Roobottom C., Traill Z. C.: Post-mortem imaging as an alternative to autopsy in the diagnosis of adult deaths: a validation study. Lancet 2012, 379, 136-142.

20. Rosenberger M. R.: Hunting shack ammunitions. Bellona, Warszawa 2017.

21. Thali M. J., Kneubuehl B. P., Bolliger S. A., Koenigsdorfer A. C., Ozdoba C., Spielvogel E., Dirnhofer R.: Forensic veterinary radiology: ballistic-radiological 3D computer tomographic reconstruction of an illegal lynx shooting in Switzerland. Forensic Sci. Int. 2007, 171, 63-66.

22. Wisniewska-Sliwinska H., Marcinkowski J.: The expert in court - the mode of appointment, requirements, responsibilities. Orzecznictwo Lekarskie 2001, 8, 33-39.

Corresponding author: Piotr Listos DVM, PhD, ul. Głeboka 30, 20-612 Lublin, Poland; e-mail: piotr.listos@up.lublin.pl 